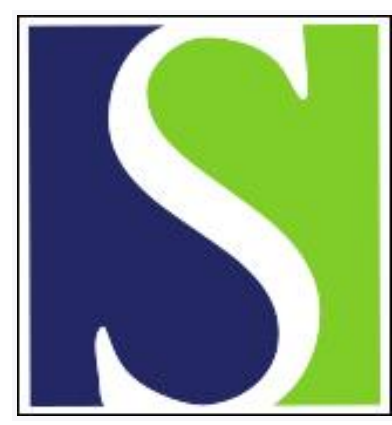

Scand J Work Environ Health 1992;18(1):18-25

https://doi.org/10.5271/sjweh.1616

Issue date: 28 Feb 1992

Primary liver cancer and occupational exposure.

by Kauppinen T, Riala R, Seitsamo J, Hernberg S

Affiliation: Institute of Occupational Health, Helsinki, Finland.

This article in PubMed: www.ncbi.nlm.nih.gov/pubmed/1313183

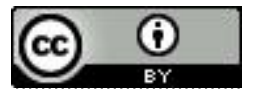




\title{
Primary liver cancer and occupational exposure
}

\author{
by Timo Kauppinen, PhD, Riitta Riala, MSc(Eng), Jorma Seitsamo, MSc, Sven Hernberg, MD ${ }^{1}$
}

\begin{abstract}
KAUPPINEN T, RIALA R, SEITSAMO J, HERNBERG S. Primary liver cancer and occupational exposure. Scand $J$ Work Environ Health 1992;18:18-25. In a dynamic population-based case-referent study on primary liver cancer and occupational exposure, the work histories of 344 cases and 861 referents, derived from the follow-up of the whole Finnish population in 1976-1978 and 1981, were analyzed by industry, occupation, and agent. After adjustment for alcohol consumption, elevated odds ratios were found for the categories other agricultural workers (mainly milkmaids), clerical workers, persons exposed to welding fumes and those exposed to other inorganic dusts (mainly silica). One possible explanation for the excess among milkmaids was exposure to dust from cattle feed contaminated with aflatoxins. The excess among clerical workers was probably due to nonoccupational factors or chance because occupational exposure was generally rare. The excesses for welding fumes and inorganic dusts, although compatible with occupational etiology, contradict the results of many previous studies carried out among workers exposed to silica dust and welders.
\end{abstract}

Key terms: aflatoxins, case-referent study, clerical workers, job-exposure matrix, milkmaids, mineral dust, silica, welding fumes.

The risk factors for primary liver cancer in humans include aflatoxin-contaminated food, hepatitis B infection, and heavy consumption of alcoholic beverages. In addition the intake of certain drugs, such as anabolic steroids, thorotrast, immunosuppressive drugs, and oral contraceptives have been associated with liver cancer. Occupational exposure to vinyl chloride has been shown to cause liver angiosarcoma, a rare form of liver cancer $(1-3)$. There is also increasing evidence that solvents, especially chlorinated hydrocarbons, may cause primary liver cancer (4-9). Other agents associated with liver cancer include asphalt fumes and chlorophenols (7).

Agents that cause hepatocellular cancer in animals are numerous. According to the data base kept by the International Agency for Research on Cancer (IARC), liver carcinogens can be found among diet-related agents such as protein pyrolysates, $\mathrm{N}$-nitrosoamines and aflatoxins, among oral contraceptives, among analgesic and sedative drugs, and among many industrial agents, such as aromatic amines, benzidine-based and other azo dyes, chlorinated hydrocarbons (eg, chloroform, carbon tetrachloride, perchloroethylene, methylene chloride, 1,2-dichloroethane, chlorobenzenes, vinyl chloride), pesticides (eg, chlordecone, toxaphene, amitrole, chlorophenols), butadiene, dioxane, diethylhexyl phthalate, 1,2-dibromoethane, and hydrazine (Dr J Wilbourn, IARC, personal communication).

In the 1980 s, the annual incidence of liver cancer in Finland was about 4/100 000 men and about 2/

\footnotetext{
1 Institute of Occupational Health, Helsinki, Finland.
}

Reprint requests to: Dr T Kauppinen, Institute of Occupational Health, Topeliuksenkatu 41 a A, SF-00250 Helsinki, Finland.
100000 women (10). These figures are much lower than in some high risk areas in Africa and Asia, where the incidence is well over $10 / 100000$ men (11). The geographic differences may partly be explained by the low level of aflatoxins in the diet and the rareness of hepatitis B infections in the countries of northern Europe. The potential risk factors for liver cancer in Finland include dietary factors, alcohol, occupational exposures, and possibly certain drugs.

The purpose of the present study was to investigate the role of occupational exposure in the etiology of primary liver cancer. Special attention was paid to solvents because a previous Finnish study has indicated an elevated risk among women (4). In addition to solvents, over 40 other agents were surveyed in the present study. This paper reports the results concerning agents other than solvents because the latter have been reported on in an earlier paper (5).

\section{Subjects and methods}

A dynamic population-based case-referent design was adopted. All cases of primary liver cancer (International Classification of Diseases, ninth revision, code 155.0) $(\mathrm{N}=618)$ reported to the Finnish Cancer Registry in 1976-1978 and 1981 were first listed as cases. Our previous study (4) had utilized the cases from 1979-1980. After exclusion of those case subjects who were alive $(\mathrm{N}=5)$, those whose diagnosis of primary liver cancer could not be confirmed $(\mathrm{N}=33$ ), and those whose relatives could not be traced $(\mathrm{N}=87)$ or did not reply to the questionnaire $(\mathrm{N}=151), 344$ cases were left for the final analysis. Two reference groups were used, 772 patients with stomach cancer reported to the Finnish Cancer Registry in 1977 and 674 persons deceased 
from coronary infarction and listed in the autopsy records of the same hospitals from which the cases came. After exclusions, the final sizes of the reference groups were $\mathbf{4 7 6}$ and $\mathbf{3 8 5}$ for the stomach cancer and coronary infarction referents, respectively. The reference groups were frequency-matched for age and gender with the case group. Because the analysis performed for the solvent study (5) gave similar results for both reference groups, they were combined.

Information on work history was collected by a postal questionnaire sent to the closest traced relative. The relatives were asked to list the employers, workplaces, occupations, and calendar years of work concerning the person under study. The use of alcohol, drugs, coffee, tea, and tobacco and leisure-time activities were also inquired about. The response rate was $71.7 \%$ for the cases and $71.0 \%$ for the combined reference group. The differences as to the category of respondent (spouse, child, sibling, other relative) between the case and reference groups were small. The source of information for the men and women was different, the main respondent being the wife for the men $(57 \%)$ but the child for the women $(61 \%)$, both in the case and reference groups. The characteristics of the subjects and the methods used to collect information have been described in more detail in our previous paper (5).

The assessment of exposure was carried out with the use of the following three mutually related approaches: (i) analysis of occupations and industries of the subjects, (ii) analysis of potential exposure to 50 agents with the use of a job-exposure matrix, and (iii) reanalysis, by a team of occupational hygienists, of the agents that indicated an increased risk according to the job-exposure matrix. The purpose of approaches 1 and 2 was to identify the occupations, industries, and agents that were associated with primary liver cancer. The third approach aimed at the validation of the results of the job-exposure matrix through the use of more reliable methods of assessment. This approach is likely to provide more valid results than the two previous ones because only those subjects whose exposure to a specific agent could be considered as definite or highly probable by the occupational hygienists were the basis for the reanalysis.

In the first approach, the occupational histories reported in the questionnaires were coded by two occupational hygienists according to the British classifications of occupations and industries to allow the use of the British job-exposure matrix. The hygienists were unaware of the case-referent status of the subjects. In addition to the entire work history, the main occupation and industry, defined as those with the longest employment, were specified for each person. The analysis of the data by occupation and industry was based on this coding. While coding the occupational histories, the hygienists listed the obvious exposures of the subjects on the basis of the work history, or in some cases on the basis of a remark written on the questionnaire by the respondent (manual bookkeeping of exposures).

In the second approach, all the occupational histories were transformed into potential exposures to 50 agents according to the job-exposure matrix constructed in Southampton, the United Kingdom (12). Each case and referent was assigned to exposure categories defined by the combination of the probability (none, low, high) and level (none, low, high) of exposure. In an attempt to condense the data for further analysis, the category with a high probability and level of exposure was renamed "high potential exposure" and analyzed separately from the joint category of all the other grades of exposure renamed "low potential exposure."

In the third approach, agents showing elevated odds ratios were reanalyzed to confirm the findings. The criteria for the selection of agents for further analysis were the following: odds ratio at least 1.5 , number of exposed cases at least 5 , and the exposure-response trend according to the job-exposure matrix not decreasing. The final assessment of exposure was conducted on the basis of the detailed work histories in the questionnaires. The case-referent status of the subject was blinded in the exposure assessment. The archives of the Institute of Occupational Health, containing reports on occupational hygienic measurements from 1950 onwards, were used as guidelines in the assessment of the probability and level of exposure. The subjects indicated by the job-exposure matrix to be potentially exposed were each reclassified according to the estimated cumulative exposure. In addition manual bookkeeping of exposures was used to identify any exposed persons whom the job-exposure matrix classified as unexposed.

The classes used for cumulative exposure were heavy, moderate, and light. Assignment to the class "heavy" required at least 10 years of work under conditions in which the level of exposure was considered to have been high. "Moderate" referred to less than 10 years' employment in high exposure or at least 10 years' employment in low exposure. "Light" referred to less than 10 years' employment in low exposure. The cut-off point between the high and low level of exposure was fixed at the concentration of the agent in the air corresponding to $50 \%$ of the threshold limit valut or the biological exposure index adopted by the American Conference of Governmental Industrial Hygienists (13). Frequent contact of the skin with an agent able to penetrate the skin was also considered to imply high exposure. The following values were used: aromatic amines (eg, aniline) $1 \mathrm{ppm}$ or dermal contact, asbestos 0.25 fibers $/ \mathrm{cm}^{3}$, beryllium $1 \mu \mathrm{g} / \mathrm{m}^{3}$, cadmium $25 \mu \mathrm{g} / \mathrm{m}^{3}$, chromium (VI) compounds $25 \mu \mathrm{g} / \mathrm{m}^{3}$, other chromium compounds $250 \mu \mathrm{g} / \mathrm{m}^{3}$, ethylene oxide $0.5 \mathrm{ppm}$, magnetic fields $0.5 \mathrm{mT}(60 \mathrm{~Hz})$, inorganic dusts $5 \mathrm{mg} / \mathrm{m}^{3}$, lead $25 \mu \mathrm{g} / \mathrm{dl}$ of blood, and welding fumes $2.5 \mathrm{mg} / \mathrm{m}^{3}$. Exposures were assessed only until the year 1966 to 
allow for a latency period of 10 years between first exposure and the end of follow-up. All of the subjects whose exposure could not be considered probable were assigned to the class "potential exposure," which was excluded from the analysis.

In all three stages of exposure assessment, the likelihood-based estimates of the odds ratio (OR) and their $95 \%$ confidence interval $(95 \% \mathrm{CI})$ were calculated by Cornfield's method (14). Because alcohol consumption is an established risk factor of primary liver cancer, its effect was controlled by the adjustment of the $O R$ in most analyses for alcohol usage $\left(O_{\mathrm{alc}}\right)$. These stratified analyses were conducted by the method developed by Gart (15).

\section{Results}

The main occupations and industries showing an association with liver cancer are presented in table 1 . After adjustment for alcohol usage, statistically significant values were found for other agricultural workers and clerical workers. All of the women in the class of other agricultural workers had worked for long periods as milkmaids. The mean duration of employment as a milkmaid was 32 years for the cases and 24 years for the referents. Two of the men in this occupational class were farm laborers, and one was a garden worker. One of the farm laborers had also worked for three years as a gardener, and both of them had worked in railroad construction. In contrast to the other agricultural workers, no excess was found for the male farmers (OR $0.77,95 \%$ CI $0.51-1.15,39$ cases) or for the farmers' wives (OR $0.63,95 \%$ CI $0.42-0.95$, 40 cases).

Table 2 shows the elevated odds ratios of the analysis with the job-exposure matrix. Agents whose odds ratios were not elevated by the criteria used included potential exposure to nitrates or nitrites or $\mathrm{N}$-nitrosoamines, herbicides, diesel fuel or fumes, wood dust, grain dust, textile dust, and contact with animals as well.

The results of further exposure assessments of agents associated with primary liver cancer according to the job-exposure matrix are presented in table 3. After ascertainment of exposure to the agents in table 2, only four agents (asbestos, other inorganic dusts, lead and its compounds, and welding fumes) had a sufficient number of subjects (at least five exposed cases) to allow statistical analysis and adjustment for alcohol consumption. Contrary to the analysis with the job-exposure matrix, most of the exposures ascertained were found among the men.

The odds ratios for asbestos approached unity after ascertainment of exposure and adjustment for alcohol consumption. No case or referent was reported to have worked in an asbestos mine or in asbestos product plants where high levels of exposure were known to have occurred. The heavily exposed case had worked between 1957-1978 as a plumber. Plumbers often used to lag pipes with insulation and work in the same premises as asbestos insulators. The heavily exposed referent manufactured fire doors and was reported to have handled asbestos frequently in a small basement shop with poor ventilation. Most of the cases

Table 1. Occupations and industries showing elevateda odds ratios for primary liver cancer without (OR) or with adjustment $\left(\mathrm{OR}_{\mathrm{alc}}\right)$ for alcohol consumption and the corresponding $95 \%$ confidence intervals $(95 \% \mathrm{Cl})$

\begin{tabular}{|c|c|c|c|c|c|}
\hline Occupation or industry & $\begin{array}{l}\text { Cases } \\
(\mathrm{N})\end{array}$ & $\mathrm{OR}^{\mathrm{b}}$ & $95 \% \mathrm{Cl}$ for $\mathrm{OR}$ & $\mathrm{OR}_{\mathrm{alc}} \mathrm{b}^{\mathrm{b}}$ & $95 \% \mathrm{Cl}$ for $\mathrm{OR}_{\mathrm{alc}}$ \\
\hline \multicolumn{6}{|l|}{ Other agricultural workers } \\
\hline $\begin{array}{l}\text { Men } \\
\text { Women } \\
\text { Both }\end{array}$ & $\begin{array}{r}3 \\
7 \\
10\end{array}$ & $\begin{array}{c}\ldots \\
2.30 \\
3.66\end{array}$ & $\begin{array}{c}\cdots \\
0.83-6.41 \\
1.43-9.38\end{array}$ & $\begin{array}{c}. \\
2.01 \\
3.46\end{array}$ & $\begin{array}{c}\cdots \\
0.69-5.82 \\
1.32-9.10\end{array}$ \\
\hline \multicolumn{6}{|l|}{ Laborers in building } \\
\hline $\begin{array}{l}\text { Men } \\
\text { Women } \\
\text { Both }\end{array}$ & $\begin{array}{l}5 \\
1 \\
6\end{array}$ & $\begin{array}{l}2.33 \\
\because . \\
2.17\end{array}$ & $\begin{array}{c}0.75-7.29 \\
\cdots \\
0.76-6.22\end{array}$ & $\begin{array}{c}1.87 \\
\cdots \\
1.87\end{array}$ & $\begin{array}{c}0.59-5.91 \\
\cdots \\
0.65-5.40\end{array}$ \\
\hline \multicolumn{6}{|l|}{ Clerical workers } \\
\hline $\begin{array}{l}\text { Men } \\
\text { Women } \\
\text { Both }\end{array}$ & $\begin{array}{r}2 \\
9 \\
11\end{array}$ & $\begin{array}{c}\cdots \\
1.89 \\
2.16\end{array}$ & $\begin{array}{c}\cdots \\
0.79-4.53 \\
0.98-4.78\end{array}$ & $\begin{array}{c}\cdots \\
2.06 \\
2.35\end{array}$ & $\begin{array}{c}\cdots \\
0.83-5.09 \\
1.04-5.30\end{array}$ \\
\hline \multicolumn{6}{|l|}{ Cooks } \\
\hline $\begin{array}{l}\text { Men } \\
\text { Women } \\
\text { Both }\end{array}$ & $\begin{array}{l}- \\
5 \\
5\end{array}$ & $\begin{array}{c}\ldots \\
3.79 \\
2.53\end{array}$ & $\begin{array}{c}\ldots \\
0.99-14.5 \\
0.78-8.23\end{array}$ & $\begin{array}{c}\ldots \\
2.98 \\
2.13\end{array}$ & $\begin{array}{c}\cdots \\
0.85-10.4 \\
0.68-6.66\end{array}$ \\
\hline \multicolumn{6}{|l|}{ Sawmilling } \\
\hline $\begin{array}{l}\text { Men } \\
\text { Women } \\
\text { Both }\end{array}$ & $\begin{array}{l}7 \\
1 \\
8\end{array}$ & $\begin{array}{c}1.96 \\
\cdots \\
1.56\end{array}$ & $\begin{array}{c}0.76-5.08 \\
\cdots \\
0.66-3.70\end{array}$ & $\begin{array}{c}1.82 \\
\cdots \\
1.45\end{array}$ & $\begin{array}{c}0.69-4.78 \\
\cdots \\
0.61-3.46\end{array}$ \\
\hline
\end{tabular}

a $O R$ at least 1.5 on the basis of at least five cases.

$\mathrm{O} O \mathrm{R}$ and $\mathrm{OR}_{\mathrm{alc}}$ not calculated when the number of observed cases was $<5$. 
Table 2. Odds ratios (OR) and $95 \%$ confidence intervals $(95 \%$ $\mathrm{Cl}$ ) for the agents indicating an elevated risk ${ }^{\mathrm{a}}$ according to the total occupational histories and a job-exposure matrix.

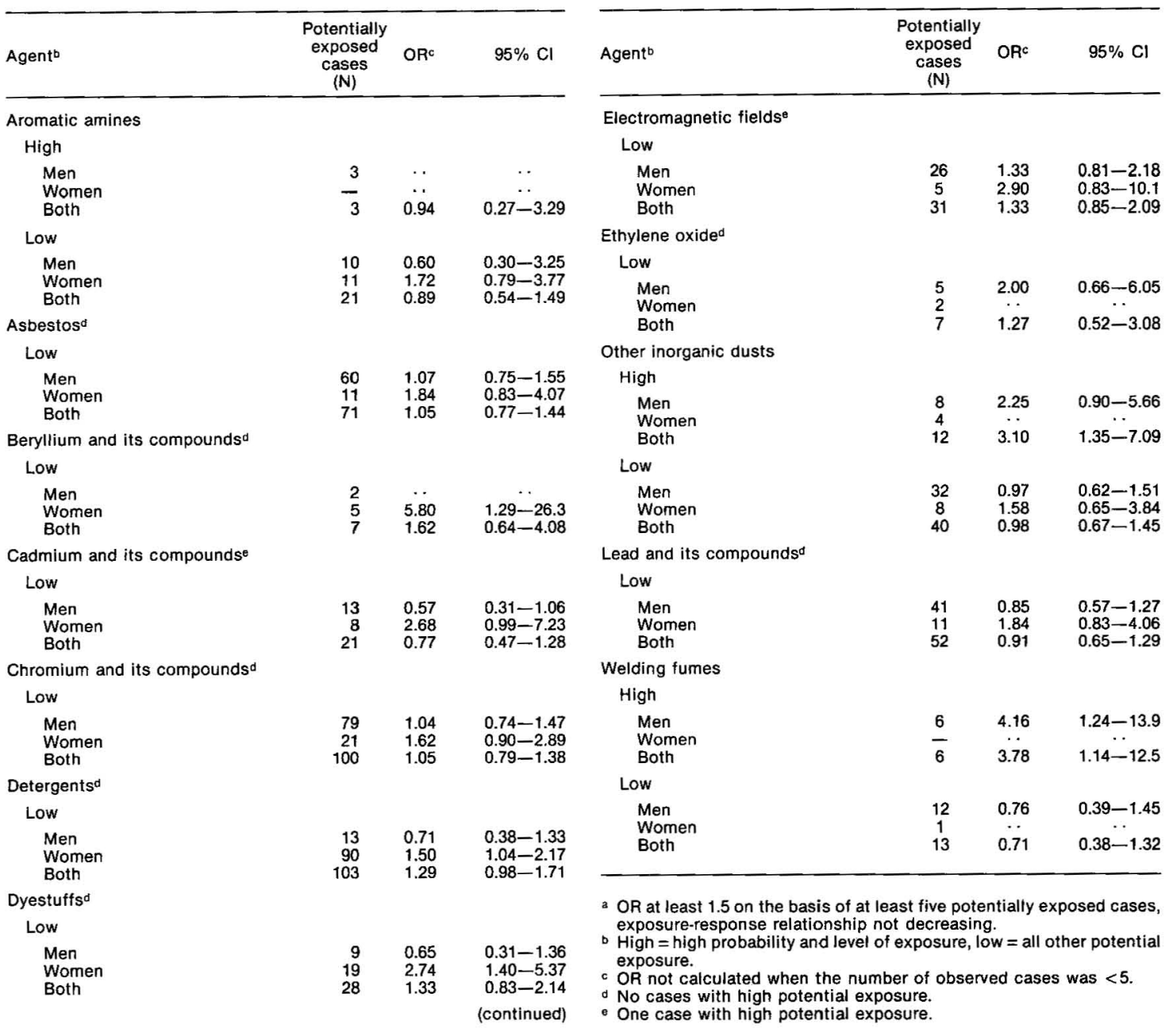

Table 2. Continued.

a OR at least 1.5 on the basis of at least five potentially exposed cases, exposure-response relationship not decreasing.

OR not calculated when the number of observed cases was $<5$.

- One case with high potential exposure. and referents were long-term construction workers or car mechanics who were considered to have been exposed to low average levels of asbestos due to its frequent occurrence in construction sites and in car maintenance, especially during the 1950 s and 1960 s.

Moderate exposure to inorganic dusts was associated with about a twofold risk of liver cancer, which was of borderline statistical significance. Only a few subjects were assigned to the heavily exposed group, and no association was observed in this group. The heavily exposed subjects were long-term stone drillers (one case, one referent) or foundry workers in dusty jobs (two referents). Most of the moderately exposed workers were long-term construction hands, masons, or construction stone workers. In addition a few workers from brick factories, china factories, and mines were included. Light exposure originated mainly from road work or short-term construction work. The inorganic dust involved was mostly stone dust containing silica or cement dust.

Lead exposure was associated with liver cancer. Elevated values were observed in the moderate exposure group, whereas no excess was found in the heavy and light exposure groups. No cases, but four referents were classified as heavily exposed. They were all long-term typesetters reported to have been frequently exposed to lead fumes or dust. The moderately exposed group included plumbers (one case, one referent), welders with probable exposure to lead (two cases), a short-term lead-battery manufacturing worker (case), a long-term car mechanic (case), an engineer of a lead white factory (referent), long-term telephone linemen (two referents), a short-term typographer (referent), and long-term workers of crystal glass factories (two referents). Short-term plumbers (one case, two referents), a short-term book printer (referent), 
Table 3. Odds ratios (OR), odds ratios adjusted for alcohol consumption $\left(O \mathrm{R}_{\text {alc }}\right)$, and the respective $95 \%$ confidence intervals $(95 \% \mathrm{Cl})$ for primary liver cancer among the men by cumulative exposure assessed by a team of occupational hygienists.

\begin{tabular}{|c|c|c|c|c|c|}
\hline Agenta & $\begin{array}{l}\text { Exposed } \\
\text { cases }(\mathrm{N})\end{array}$ & $O R^{b}$ & $95 \% \mathrm{Cl}$ for $\mathrm{OR}$ & $O R_{a l c}^{b}$ & $95 \% \mathrm{Cl}$ for $\mathrm{OR}_{\mathrm{alc}}$ \\
\hline \multicolumn{6}{|l|}{ Asbestos } \\
\hline $\begin{array}{l}\text { Heavy } \\
\text { Moderate } \\
\text { Light } \\
\text { All }\end{array}$ & $\begin{array}{r}1 \\
16 \\
1 \\
18\end{array}$ & $\begin{array}{c}\ldots \\
1.21 \\
\because \\
1.23\end{array}$ & $\begin{array}{c}\cdots \\
0.66-2.25 \\
\cdots \\
0.68-2.23\end{array}$ & $\begin{array}{c}\ldots \\
1.15 \\
\ddot{1.17}\end{array}$ & $\begin{array}{c}\cdots \\
0.61-2.19 \\
\cdots \\
0.65-2.12\end{array}$ \\
\hline \multicolumn{6}{|c|}{ Other inorganic dusts } \\
\hline $\begin{array}{l}\text { Heavy } \\
\text { Moderate } \\
\text { Light } \\
\text { All }\end{array}$ & $\begin{array}{r}1 \\
11 \\
10 \\
22\end{array}$ & $\begin{array}{l}\ldots \\
2.17 \\
0.99 \\
1.38\end{array}$ & $\begin{array}{c}\cdots \\
0.98-4.82 \\
0.47-2.06 \\
0.80-2.38\end{array}$ & $\begin{array}{c}\ldots \\
2.12 \\
0.94 \\
1.34\end{array}$ & $\begin{array}{c}\cdots \\
0.95-4.74 \\
0.45-1.98 \\
0.77-2.32\end{array}$ \\
\hline \multicolumn{6}{|c|}{ Lead and its compounds } \\
\hline $\begin{array}{l}\text { Heavy } \\
\text { Moderate } \\
\text { Light } \\
\text { All }\end{array}$ & $\begin{array}{l}- \\
1 \\
6\end{array}$ & $\begin{array}{c}\cdots \\
2.12 \\
\cdots \\
1.09\end{array}$ & $\begin{array}{c}\cdots \\
0.68-6.66 \\
\cdots \\
0.42-2.81\end{array}$ & $\begin{array}{c}\ldots \\
2.28 \\
\ddot{1.14}\end{array}$ & $\begin{array}{c}\cdots \\
0.68-7.67 \\
\cdots \\
0.44-2.98\end{array}$ \\
\hline \multicolumn{6}{|c|}{ Welding fumes } \\
\hline $\begin{array}{l}\text { Heavy } \\
\text { Moderate } \\
\text { Light } \\
\text { All }\end{array}$ & $\begin{array}{r}5 \\
1 \\
-6\end{array}$ & $\begin{array}{c}13.5 \\
\cdots \\
\cdots \\
1.35\end{array}$ & $\begin{array}{c}2.07-87.6 \\
\cdots \\
\cdots \\
0.52-3.53\end{array}$ & $\begin{array}{c}13.4 \\
\cdots \\
\cdots \\
1.38\end{array}$ & $\begin{array}{c}2.02-88.1 \\
\ldots \\
\cdots \\
0.52-3.64\end{array}$ \\
\hline
\end{tabular}

a Heavy $=$ duration $\geq 10$ years at a high level, moderate $=\geq 10$ years at a low level or $<10$ years at a high level, light $=<10$ years at a low level. For definitions of the low and high levels, see the Subjects and Methods section.

${ }^{b} \mathrm{OR}$ and $\mathrm{OR}_{\mathrm{alc}}$ not calculated when the number of observed cases was $<5$.

and a short-term worker in a cable factory (referent) were assigned to the light exposure group.

After adjustment for alcohol consumption, an excess of liver cancer remained among the men heavily exposed to welding fumes. The heavily exposed group consisted entirely of long-term welders (five cases, one referent). Moderate exposure was assigned to longterm metal-plate workers (one case, two referents), two sheet metal workers (referents), two fitters (referents), one foundry worker (referent), and one maintenance worker (referent). Three referents had experienced light exposure, two as maintenance workers in the forest product industry and one while working in an aircraft factory. The questionnaire included a specific question about the welding activities of the subjects.

Exposure to aromatic amines was considered as probable only for one male case and one male referent. The case had worked in 1937-1939 in a rubber factory and the referent as a supervisor in another rubber factory in 1946-1972. Naphthyl amines were commonly used as antioxidants of rubber from the early 1930 s to the early 1950 s. Since then numerous derivatives of naphthyl amines or phenylene diamines have been used for the same purpose.

No exposure to beryllium could be confirmed in the further analysis. Exposure to beryllium is very rare in Finland according to the Register of Employees Occupationally Exposed to Carcinogens (16), and the situation has been similar also in the past.

Cadmium exposure was considered as probable only for one case and three referents. The case was a shipyard welder who had probably done hard soldering of pipes. Two of the referents were long-term workers in art glass factories where cadmium pigments were used. One referent was a long-term supervisor in a paint factory which has produced cadmium-containing paints.

Chromium exposure could be assigned with high probability only to two cases (one man, one woman) and five referents (all men). The male case had worked as a welder in 1956-1981 in several shipyards and machine shops using stainless steel. Three of the referents were long-term metal platers or maintenance workers in paper mills with likely exposure to welding fumes from stainless steel. The two other referents were a long-term spray painter in a machine shop and a supervisor of a paint manufacturing plant in 19471974, where dyestuff dust was reported to have been present frequently in the workroom air. All of the men were exposed mainly to chromium (VI) compounds, whereas the only woman was a seamstress in a glove factory that used leather tanned with chromium (III) compounds.

Most of the subjects exposed to detergents were housewives. A few kitchen workers, hairdressers, barbers, and cleaning workers had also probably had frequent skin contact with detergents.

Exposure to dyestuffs was obvious only for three subjects. One case had worked for 25 years in the manual printing of wallpaper, and two referents as dyers, each for about one year.

When exposure to magnetic fields was reassessed, only three cases and 14 referents could be considered exposed. The heavily exposed group included longterm electricians (two cases, eight referents) and a coil 
winder (referent). Four referents had experienced moderate exposure, one as a nickel plater, one as an electrical assembler and coupler, one as an electrical assembler and coil winder, and one as a short-term electrician. Light exposure was assigned to two shortterm electrical assemblers (one case, one referent). Most of the exposed persons had worked in the vicinity of $60 \mathrm{~Hz}$ alternating current fields.

Ethylene oxide has been commonly used only in the sterilization of hospital instruments in Finland, and no case or referent had worked in such a job according to the reported work histories.

Chlorophenol exposure was also checked because of the slight excess of liver cancer observed in a Swedish study (7) and because there was an indicated association for sawmilling in our study (table 1). Chlorophenols were frequently used as fungicides in Finnish sawmills from the late 1940 s to the early 1980s. Two exposed cases were long-term sawmill workers. One had had frequent contact with the chlorophenol preparation as dust and solution, and the other was a technician in a sawmill where many workers were still heavily exposed to chlorophenols in the late $1970 \mathrm{~s}$ according to measurements carried out by the Institute of Occupational Health. The three referents had all been working as timber yard workers handling boards treated with chlorophenols.

\section{Discussion}

The validity aspects of the study have been discussed in our previous paper (5). In brief, a priori selection was unlikely because the case series contained all liver cancer patients of Finland during four years. Although the nonresponse rate was rather high, the case and referent series were symmetrical with respect to nonresponse. Alcohol consumption as a potential confounder was controlled by stratification. Hepatitis B infection and the use of oral contraceptives were rare and unlikely to exert a significant confounding effect on the results. Blinding and systematic methods in the exposure assessment were used to avoid information bias. Some other factors (quality of work histories, use of a job-exposure matrix) possibly causing misclassification of exposure are presented in the following discussion in connection with specific results.

The results of this study suggest an increased risk of primary liver cancer among the categories other agricultural workers and clerical workers and among those exposed to welding fumes or mineral dusts. In addition, smaller excesses were identified for 10 other chemical agents when the occupational histories were analyzed by the British job-exposure matrix. Nine of these excesses appeared only among the women.

Most of the persons in the occupational group other agricultural workers were milkmaids who took care of cows, pigs, and poultry in larger barns and were usually exposed via inhalation to various agricultural dusts and gases, including hay, grain, fodder and animal-generated dusts, mold spores, ammonia, and sulfur-containing gases. Indications of an increased risk among farm laborers have been reported in three studies in the United States $(8,17,18)$, but the excesses were demonstrated mainly for the men, whose exposure pattern was probably different from that of the Finnish milkmaids. A Danish study has suggested an increased risk of liver cancer for workers exposed via inhalation to aflatoxins originating from imported crops used by the livestock feed-processing industry. Especially imported peanut oil cakes were reported to have contained high concentrations of aflatoxin $B_{1}$ in 19761978 , about $1000 \mu \mathrm{g} / \mathrm{kg}$ on the average with the maximal values exceeding $5300 \mu \mathrm{g} / \mathrm{kg}$ (19). Peanut oil cakes have been used as ingredients in many commercial fodder products for cattle and poultry also in Finland. The imported amounts prior to 1970 are unknown, but, according to the annual reports of the Finnish Institute of Agrochemistry, about 2800 samples of peanut oil cakes or powder were analyzed in 1941-1958; this amount is $8-9 \%$ of all the fodder samples analyzed. The available documents indicate that also slightly moldy batches passed the control with a statement that they would not endure a long storage period (20). Unlike the farmers' wives, who worked on small farms and used mainly domestic animal feeds, many milkmaids were employed by estates or large farms using commercial fodder products possibly contaminated with aflatoxins. Therefore, even though the possibility of a chance finding cannot be ruled out, the alternative explanation for the excess among milkmaids might be occupational exposure to aflatoxins.

The observed excess for clerical workers can probably be explained by nonoccupational factors or by chance, because this group is not usually occupationally exposed to chemical agents.

The fact that most of the chemical agents that had an association with primary liver cancer in the preliminary analysis (the job-exposure matrix approach) appeared only among women raises the question of whether women are biologically more susceptible than men to liver cancer due to exposure to chemicals. The alternative explanation is a differential information bias. In order to test this possibility, we estimated the completeness and accuracy of the occupational histories of the cases and referents. It turned out that the occupational histories of the female cases included, on the average, $13 \%$ more periods of work than those of the female referents ( 1.81 periods versus 1.60 periods). Similar asymmetry was not observed for the men (1.74 versus 1.81 , respectively). This is not necessarily evidence of bias if the female cases actually had changed their occupation more frequently than the referents. However, the accuracy of the occupational histories was also better for the female cases than for the female referents. The accuracy was tested by the reporting of the first year of the occupational history, which was 
specified for $65 \%$ of the female cases, but for only $55 \%$ of the female referents. Again, the situation was the opposite among the men, the corresponding percentages being 57 for the cases and 71 for the referents. It seems reasonable to conclude that there was a differential reporting bias in the occupational histories of the women. This occurrence may explain most of the small excesses observed in the analysis with the job-exposure matrix. When the exposures of the women were blindly reassessed by the occupational hygienists, none of the associations remained, and this occurrence also indicated that the findings were probably false positive.

The validity of the job-exposure matrix in occupational epidemiology has been questioned because of the inevitable misclassification which is inherent in general job-exposure matrices covering the whole scale of industries and occupations. We estimated the magnitude of the misclassification bias of the British jobexposure matrix in the context of the present study (21). This job-exposure matrix turned out to work reasonably well provided that only probable, high-level exposure was considered as true exposure and the agent was not too rare (more than about $1 \%$ of the population exposed). If all potential exposure assigned by a job-exposure matrix is accepted as true exposure, misclassification bias is strong, and it is not possible to detect even true risks that are moderately high. In the present study, the job-exposure matrix analysis would have revealed a true fivefold risk for about $\mathbf{4 0}$ agents and a twofold risk for about 30 agents out of the 50 included in the job-exposure matrix. For about 10 rare agents the job-exposure matrix was able to detect only high risks (over fivefold).

The only chemical agents that showed elevated odds ratios after reassessment by occupational hygienists and adjustment for alcohol use were welding fumes and other inorganic dusts (mineral dusts mainly). Heavy exposure to welding fumes was significantly associated with liver cancer, and the latency period between the onset of exposure and the diagnosis of liver cancer was more than 10 years for each case. There was also some evidence of an exposure-response relationship (table 3). In spite of these indications of occupational etiology, this result may be a chance finding because the numerous epidemiologic studies on cancer risks among welders have not shown similar excesses. (See, eg, reference 22.) The same seems to be true also for the observed excess among persons exposed to silica or other mineral dusts; the risk of liver cancer has rarely been elevated in other epidemiologic studies. (See, eg, reference 23.)

In conclusion, we found excesses of primary liver cancer among milkmaids probably exposed to aflatoxins, clerical workers, welders, and men exposed to mineral dusts. The occupational etiology can be considered plausible for milkmaids, but not for the other associations, because these findings are not clearly sup- ported by the results of other studies. However, these associations warrant careful checking in future studies addressing liver cancer. A relative risk of about two or more could be excluded with reasonable certainty for about 30 agents. Thus the risk due to exposure to chlorinated hydrocarbon solvents reported in our earlier paper (5) and the risk for milkmaids possibly exposed to aflatoxins are the main findings of the entire study.

\section{Acknowledgments}

We are grateful to the Finnish Cancer Registry for providing us with the cases and one series of referents. We would also like to thank Drs B Pannett and D Coggon, Environmental Epidemiology Unit, Medical Research Council, Southampton, for their permission to use their job-exposure matrix, Dr U Asikainen for the verification of the diagnoses, Dr M Hietanen and $\mathrm{Mr}$ A Anttila for their contribution to the exposure assessment, Dr J Wilbourn, International Agency for Research on Cancer, Lyon, for providing us information about agents causing liver cancer in animals, Dr K Varimo, Finnish Institute of Agrochemistry, for her valuable information in the interpretation of the results, Ms T Kaustia for her linguistic revision of the manuscript, and Ms P Havana for her technical assistance during the study.

\section{References}

1. Alderson M. Occupational cancer. London: Butterworths, 1986:164-165.

2. International Agency for Research on Cancer (IARC). Alcohol drinking. Lyon: IARC, 1988. (IARC monographs on the evaluation of the carcinogenic risks to humans; vol 44).

3. International Agency for Research on Cancer (IARC). Overall evaluations of carcinogenicity: an updating of IARC monographs volumes 1 to 42. Lyon: IARC, 1987. (IARC monographs on the evaluation of the carcinogenic risks to humans; suppl 7).

4. Hernberg S, Korkala ML, Asikainen U, Riala R. Primary liver cancer and exposure to solvents. Int Arch Occup Environ Health 1984;54:147-53.

5. Hernberg S, Kauppinen T, Riala R, Korkala ML, Asikainen U. Increased risk for primary liver cancer among women exposed to solvents. Scand J Work Environ Health 1988;14:356-65.

6. Blair A, Decoufle P, Grauman D. Causes of death among laundry and dry cleaning workers. Am J Public Health 1979;69:508-11.

7. Hardell L, Bengtsson NO, Jonsson U, Eriksson S, Larsson LG. Aetiological aspects on primary liver cancer with special regard to alcohol, organic solvents and acute intermittent porphyria - an epidemiological investigation. Br J Cancer 1984;50:389-97.

8. Stemhagen A, Slade J, Altman R, Bill J. Occupational risk factors and liver cancer: a retrospective case-control study of liver cancer in New Jersey. Am J Epidemiol 1983;117:443-54.

9. Lynge E, Thygesen L. Primary liver cancer among women in laundry and dry-cleaning work in Denmark. Scand J Work Environ Health 1990;16:108-12. 
10. Finnish Cancer Registry. Cancer incidence in Finland 1985. Helsinki: Finnish Cancer Registry, 1989. (Publication no 43.)

11. Parkin DM, Doll RD, Fellingham SA. Estimates of the worldwide frequency of twelve major cancers. Bull WHO $1984 ; 62: 163-82$.

12. Pannett B, Coggon D, Acheson ED. A job-exposure matrix for use in population based studies in England and Wales. Br J Ind Med 1985;42:777-83.

13. American Conference of Governmental Industrial Hygienists (ACGIH). Threshold limit values and biological exposure indices for 1988-89. Cincinnati, $\mathrm{OH}$ : ACGIH, 1988.

14. Cornfield J. A statistical problem arising from retrospective studies. In: Proceedings of the 3rd Berkeley symposium; vol 4. Berkeley, CA: University of California Press, 1956:135-48.

15. Gart JJ. Point interval estimation of the common odds ratio in the combination of $2 \times 2$ tables with fixed marginals. Biometrika 1970;57:471-5.

16. Heikkilä P, Savela A, Vuorela R, Partanen T. Employees exposed to carcinogens in Finland in 1986. Helsinki: Institute of Occupational Health, 1988. (Reviews; no 13$)$.

17. Suarez L, Weiss NS, Martin J. Primary liver cancer death and occupation in Texas. Am J Ind Med 1989; 15:167-75.

18. Austin H, Delzell E, Grufferman S, Levine R, Morrison AS, Stolley PD, Cole P. Case-control study of hepatocellular carcinoma, occupation, and chemical exposures. J Occup Med 1987;29:665-9.

19. Olsen J, Dragsted L, Autrup H. Cancer risk and occupational exposure to aflatoxins in Denmark. Br J Cancer 1988;58:392-6.

20. Institute of Agrochemistry. Annual reports. Helsinki: Institute of Agrochemistry, 1941-1958.

21. Kauppinen TP, Mutanen PO, Seitsamo JT. Magnitude of misclassification bias when using a job-exposure matrix. Scand J Work Environ Health. In press.

22. International Agency for Research on Cancer (IARC). Chromium, nickel and welding. Lyon: IARC, 1990. (IARC monographs on the evaluation of the carcinogenic risks to humans; vol 49).

23. International Agency for Research on Cancer (IARC). Silica and some silicates. Lyon: IARC, 1987. (IARC monographs on the evaluation of the carcinogenic risks to humans; vol 42).

Received for publication: 15 April 1991 